\title{
Performance Assessment of Communication Network in WAMS
}

\author{
Kiran Gajrani ${ }^{1}$, Krishan Gopal Sharma ${ }^{2}$ and Annapurna Bhargava ${ }^{3}$ \\ ${ }^{1}$ Department of Electrical Engineering, Rajasthan Technical University, Kota, India \\ K_gajrani@rediffmail.com \\ ${ }^{2}$ Krishan Gopal Sharma, Government Engineering College, Ajmer, India \\ Kgsharma050rediffmail.com \\ ${ }^{3}$ Department of Electrical Engineering, Rajasthan Technical University, Kota, India \\ Ab_eck@sify.com
}

\begin{abstract}
Wide Area Measurement Systems (WAMS) based on Synchronized Measurement Technology (SMT) is getting considerable attention worldwide from the power system engineers in last few years. The fast and synchronized measurements facilitate the real time Wide Area Monitoring and Control (WAMC) of the power system. The backbone of WAMS is high performance communication infrastructure. Network designer has vast variety of architecture, protocol and communication medium. The medium should be selected in such a manner that it provides guaranteed bandwidth for the utilities. In this paper, we have simulated Phasor Measurement Unit (PMUs) data traffic in OPNET, and then created scenarios with different routing protocols. The performance of WAMS has also been analyzed in presence of varying background traffic and main link failure. Simulation results have been pursued in such a way that under worst situation the 'end to end delay' is within an acceptable range.
\end{abstract}

\section{KEYWORDS}

PMU, WAMS, communication network, routing protocol, OPNET.

\section{Introduction}

In today's environment, the need of power has increased manifold, while the power system assets, due to limited resources have not developed in the same proportions, in order to meet the growing demand. In this stressed scenario, the grid is not able to cope up with any contingency due to line outages or generator outages. The triggering event may lead cumulatively, outages, which in turn, may result into a complete blackout. One recent example is August 2003, a massive blackout in North East United States. The major reasons for August 2003 blackout as listed by the US-Canada Power System Outage Task Force [1] were; inadequate inter-regional visibility over the power system and lack of adequate backup capability of that system. One of the major recommendations of the report was to develop WAMS for wide area situational awareness. WAMS provide the real time monitoring, protection and control of complex power system. The core of WAMS is the communication network, which is to be selected in terms of latency and reliability; hence, selection of architecture, network protocols, and communication medium will play a vital role in successful implementation of WAMS.

The author stated in [2], that the performance of WAMC systems is mainly depend on the performance of Information and Communication Technology (ICT) infrastructure that supports the power system. The paper [3] addresses the analysis of PMU systems and communication architectures by implementing shared and dedicated communication network scenarios. The author proposes [4] real time control, communication and computation schemes to control the power system dynamics. In this paper, the performance of WAMS communication network has been analysed with PMUs/PDCs data traffic along with varying background traffic in OPNET.

DOI : $10.5121 /$ ijdps.2012.3611 
The different routing protocols have also been simulated in terms of fault tolerance using optical fiber medium. We have not considered the protocols used at the service provider end; like MPLS and assumed committed data rate across the network. The paper is organised as follows; Section II provides the background of WAMS, its architecture, and the placement of PMUs, which is based on Binary Particle Swarm Optimization (BPSO) methodology for complete power system observability. It also gives insight on IEEE C37-118.2.2011; standard for data transfer over WAMS. Section III deals with the features of different communication mediums and routing protocols. Section IV demonstrates the commonly used simulation tools and explains the different scenarios created in simulation model using OPNET. Section V discusses the result of different scenarios. Finally in section VI the conclusion and future work are given.

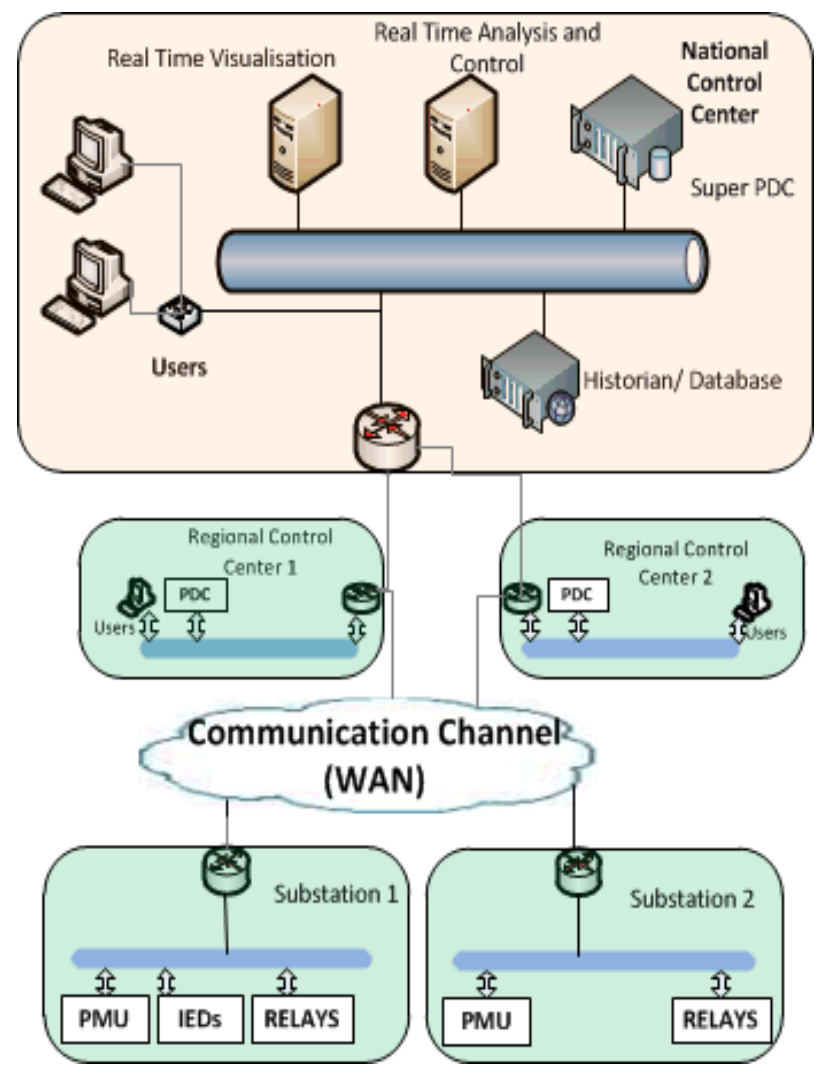

Figure 1. WAMS Communication Network

\section{WAMS Overview}

The main building block of WAMS is PMU, which provides GPS clock stamped synchronized phasors from rate of 30 frames/sec to even 120 frames/sec. Figure 1 explains the architecture of WAMS. It consists of substations, communication channels, regional control centers, and national control center. Substations are equipped with PMUs, Relays, and Intelligent Electronic Devices (IEDs). Communication within the substation takes place through Local Area Network (LAN), where Ethernet is generally used. The data from remotely scattered PMUs are transmitted to Phasor Data Concentrator (PDC) at the regional control centers. The PDC realigns the data and forwards to super PDC at national control center, where the data is used for various applications such as real time visualization, monitoring, protection, control, and alarm 
for critical situations. The Wide Area Monitoring and Control (WAMC) send control commands to critical relays/circuit breakers during urgent situations. The data is used for State Estimation, which is further required for stability study of electric grid. A large amount of data is used for storage, which is utilized for post term analysis of blackout/critical events.

Deployment of PMUs are progressing in phased manner all across the globe due to its associated cost, hence suitable criterion has to be used and adopted for the placement of minimum possible PMUs, to observe the complete power system. Figure 2 shows the placement of minimum possible PMUs for complete observability in IEEE 14 bus system based on BPSO methodology [5].

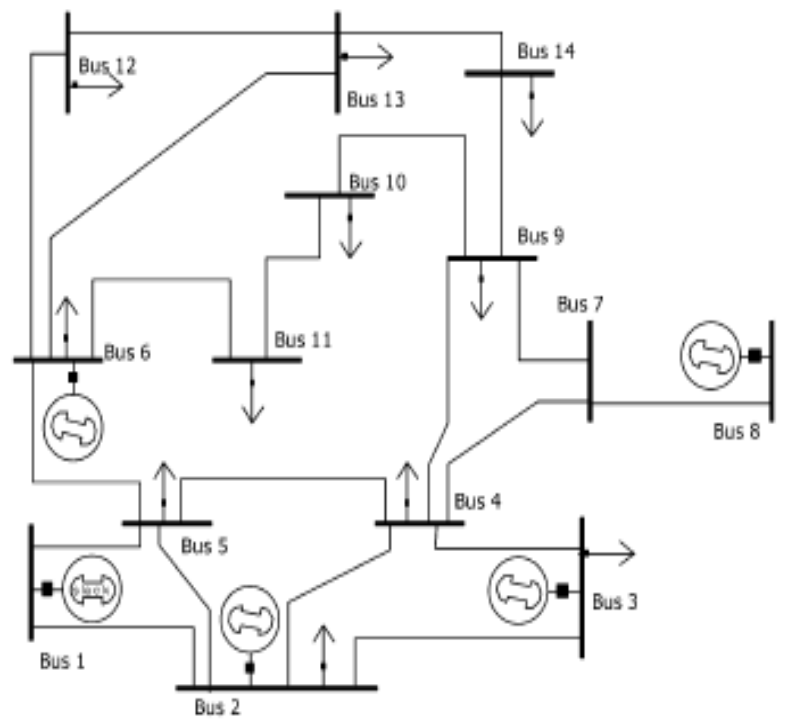

Figure 2. IEEE 14-bus system

The IEEE C37.118 standard was developed for synchronized phasor measurements used in electric power systems. To simplify and facilitate the use of SMT with other communication protocols, the IEEE C.37.118 was divided into two parts, one part (IEEE C37-118.1.2011) deals with measurement whereas other part (IEEE C37-118.2.2011) deals with data transfer. The IEEE C37-118.2.2011 [6] standard does not specify any communication medium; however, various message types have defined as data, configuration, header and command. The first three message types are transmitted from PMU/PDC that serve as the data source, and the last is received by PMU/PDC in case of any control signal issued by national control center. The IEEE data frame format has specified in Table1. If a packet contains data of a phasor, an analog word and a digital status word, it requires 38 bytes in IEEE floating-point and 28 bytes in fixed integer type. Phasor packets are transmitted over Wide Area Network (WAN) using Internet Protocol (IP). Transmission Control Protocol (TCP) / User Datagram Protocol (UDP) is used to make the packet compatible to network communication. TCP is a reliable and connection oriented protocol, which uses congestion, windowing and acknowledgement to ensure error free data transmission. It can be used to send control commands by the control center in case of any emergency for opening of circuit breaker contacts or for relay operation. As TCP has very high overhead, it may not be a feasible choice for high-speed bulk data transfer from PMUs to PDC. UDP is a better choice for PMUs to PDC data transfer, as it does not require any acknowledgement from the destination. Table 2 depicts the overhead for different network communication protocols. 


\section{Communication Infrastructure}

WAMS require a high performance communication infrastructure to transfer data from substations to control center or vice versa. Throughput (packets/sec), latency, and reliability (Bit Error Rate) are the primary factors for choosing the communication channel for WAMS [7]. Communication mediums are classified as; Power Line Carrier Communication (PLCC), Satellite Communication, Wireless Communication, and Optical Fiber Communication. Table 3 shows the typical values of different communication mediums. Network routing protocols are used to find the best path within the communication networks as well as alternate path in case of link failure and congestion. Factors that differentiate one routing protocol from another include the speed adapted to topology changes (convergence), the ability to choose the best route among multiple routes (route calculation), and the amount of network traffic that the routing protocol creates itself.

Table 1. Data frame format

\begin{tabular}{|c|c|c|}
\hline Fields & Floating Point & Integer Type \\
\hline Sync Word & 2 Byte & 2 Byte \\
\hline Frame Size & 2 Byte & 2 Byte \\
\hline ID Code & 2 Byte & 2 Byte \\
\hline $\begin{array}{c}\text { Second-of Century } \\
\text { (SOC) }\end{array}$ & 4 Byte & 4 Byte \\
\hline Fracsec & 4 Byte & 4 Byte \\
\hline Phasors & 8 xo of & 4 x No of \\
& Phasor & Phasor \\
\hline Freq & 4 Byte & 2 Byte \\
\hline Dfreq & 4 Byte & 2 Byte \\
\hline Analog & $\begin{array}{c}4 \text { X No of } \\
\text { ANNMR field }\end{array}$ & $\begin{array}{c}2 \times \text { No of } \\
\text { ANNMR field }\end{array}$ \\
\hline Digital & $2 \times$ No of & $2 \times$ No of \\
& DGNMR field & DGNMR field \\
\hline CHK & 2 Byte & 2 Byte \\
\hline
\end{tabular}

Routing Information Protocol (RIP) is a distance vector protocol, which uses number of hops in the network to determine the best route. Open Short Path First (OSPF) is a link state routing protocol, which uses bandwidth of the link to decide the best path. Enhanced Interior Gateway Routing Protocol (EIGRP) is hybrid routing protocol, which uses bandwidth, delay, load, reliability and maximum transmission unit to choose the best path.

Table 2. Overhead of network communication protocols

\begin{tabular}{|l|l|}
\hline Protocols & Overhead \\
\hline IP & 20 bytes \\
\hline TCP & 20 bytes \\
\hline UDP & 8 bytes \\
\hline Ethernet & 24 bytes \\
\hline
\end{tabular}

It is clearly visible from Table 3 that Optical fiber is the best option in terms of high bandwidth with lowest latency. It would be best to use high bandwidth optical fiber to provide core network as well as last mile connectivity; however, it is not feasible due to high cost associated with the bandwidth. We need to find the correct combination of communication medium, bandwidth and network protocols to ensure delivery of data within acceptable limit. The 
International Journal of Distributed and Parallel Systems (IJDPS) Vol.3, No.6, November 2012

permissible time for data transfer from PMUs to regional PDC is $20 \mathrm{~ms}$, from regional PDCs to super PDC is $40 \mathrm{~ms}$ and from national control center to relay at substation is $50 \mathrm{~ms}$ [8].

Table 3. Typical values of communication mediums

\begin{tabular}{|l|l|l|l|}
\hline \multicolumn{1}{|c|}{ Communication Medium } & \multicolumn{1}{|c|}{ Throughput } & \multicolumn{1}{c|}{$\begin{array}{c}\text { Latency } \\
(\mathrm{ms})\end{array}$} & \multicolumn{1}{|c|}{$\begin{array}{c}\text { Bit Error } \\
\text { Rate }\end{array}$} \\
\hline Power Line Carrier Communication & $256 \mathrm{kbps}-2.7 \mathrm{Mbps}$ & $150-350$ & $<10^{-2}$ \\
\hline Satellite Communication & $256 \mathrm{kbps}-1.0 \mathrm{Mbps}$ & $1000-1400$ & $10^{-7}$ \\
\hline Wireless Communication & $75 \mathrm{mbps}$ & $100-150$ & $10^{-7}$ to $10^{-12}$ \\
\hline Optical Fiber Communication & $10 \mathrm{Gbps}$ & $100-150$ & $10^{-15}$ \\
\hline
\end{tabular}

\section{Modeling and Simulation}

There are various network simulators available in the market to simulate different network architectures and protocols in real time. These are powerful tools to evaluate the performance under different conditions. Table 4 shows the features of most commonly used simulators; OPNET and NS2.

Table 4. Features of NS2 and OPNET

\begin{tabular}{|l|l|}
\hline NS2 & OPNET \\
\hline Discrete Event Simulator & Discrete Event Simulator \\
\hline Open Source & Commercially Available \\
\hline Poor Documentation & Up to date Documentation \\
\hline Complicated & Easy \\
\hline $\begin{array}{l}\text { Having abundant model data base but } \\
\text { does not support Vendor equipments }\end{array}$ & $\begin{array}{l}\text { Having abundant model data base, } \\
\text { also support Vendor equipments }\end{array}$ \\
\hline Programming Oriented framework & $\begin{array}{l}\text { Graphical user Interface along with } \\
\text { Programming Oriented framework }\end{array}$ \\
\hline
\end{tabular}

The two simulators are compared from the simulation model database point of view. The network simulator software, OPNET is adopted in this paper. We have simulated the minimum number of PMUs required for IEEE 14 bus system. Figure 3 shows the network simulation model of WAMS [9]. Subnet_1 represents the PMU installed at bus number 1 connected to Ethernet switch and router through 100 base T (100 Mbps) link. Similarly, other subnets (2, 6, 8 , and 3) represent the PMUs installed at respective buses. Subnet_1, subnet_2 and subnet_6 are connected to Regional control center 1 subnet, which consists of server based Regional_PDC1 and five meshed routers. Similarly, subnet_3 and subnet_8 are connected to Regional control center 2 subnet which consist of Regional_PDC2 and five meshed routers. National control center subnet receives the PMU measurements from regional control center 1 and regional control center 2 .

The super PDC realigns the PMUs measurement received from regional control centers, and is used for various applications. The control commands are sent back to relay/circuit breakers to isolate the faulty section in case of any emergency. The national control center subnet contains Super_ PDC and WAMC which are connected to switch and router through 100 base T link. The PMU subnets, regional control center subnets and national control center subnet are connected to each other via PPP EI (2 Mbps) link. 


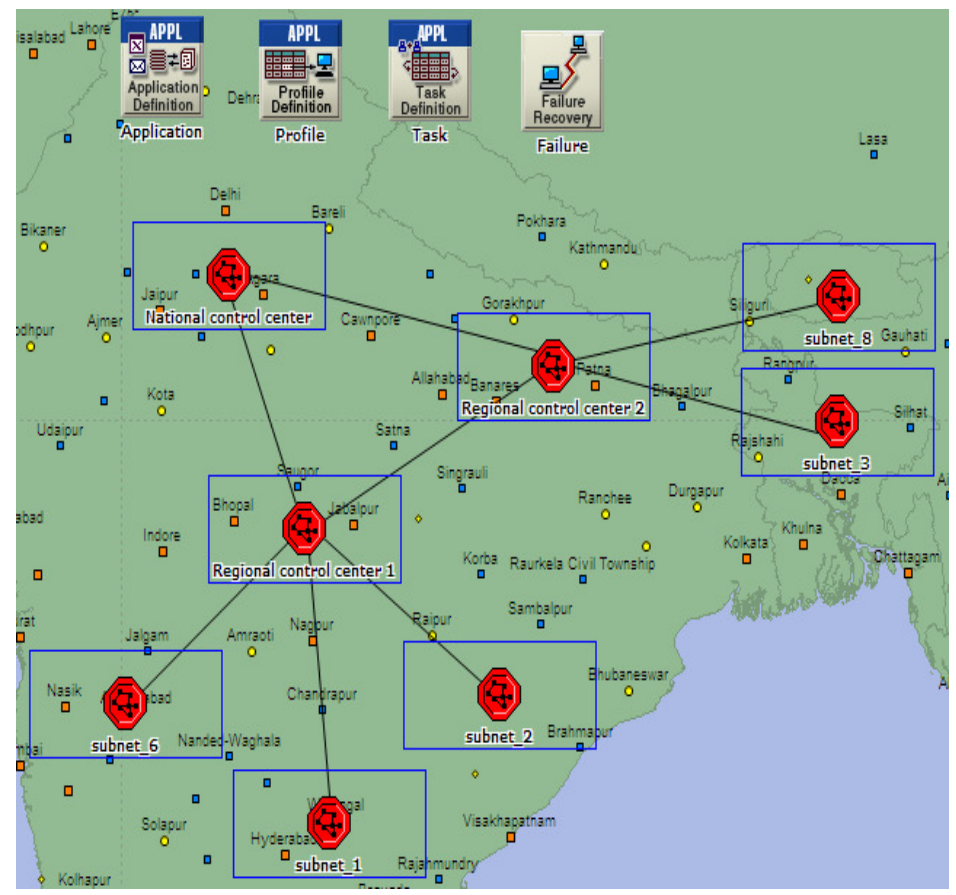

Figure 3. Simulated WAMS network topology

The network traffic can be modeled by setting up various application attributes. OPNET supports standard network applications like File Transfer Protocol (FTP), web, e-mail, remote login, video conferencing, print and voice. PMU traffic requirement does not match with any of the standard network applications, so custom application has been configured using task manager. PMU generates 30 packets per second, each of 38 bytes destined to PDC at regional control centers using UDP protocol. PDC at regional control center 1 receives 90 packets per second from three PMUs and generates 30 new packets each of 114 bytes destined to super PDC at national control center using UDP protocol. Similarly, PDC at regional control center 2 receives 60 packets per second from two PMUs and generates 30 new packets per second, each of 76 bytes destined to super PDC at national control using UDP protocol. WAMC sends control commands in case of emergency situation of the size 100 byte using TCP protocol to relay/circuit breaker at substation and relay/circuit breaker acknowledges with 10 bytes signal.

We have simulated the scenario for $2400 \mathrm{sec}$. Initially the network was loaded with PMUs traffic only but to simulate the real time scenario, background traffic was added with the help of the demand model. Background traffic of 1024 Kbits, which is 50\% of E1 link bandwidth, added from $300 \mathrm{sec}$ to $1600 \mathrm{sec}$. The main link between regional control center 1 and national control center failed at $500 \mathrm{sec}$ and recovered at $1000 \mathrm{sec}$, then one of the links between internal meshed routers of regional control center 2 failed at $1100 \mathrm{sec}$ and recovered at $1700 \mathrm{sec}$. Also in simulation, the link between PDC of regional control center 2 to super PDC at national control center failed at $1200 \mathrm{sec}$ and recovered at $1800 \mathrm{sec}$.

\section{Results}

The analysis of simulation results can be presented into many individual components to understand the network protocols and their behaviour under different conditions. When network topology changes, each router individually runs a routing algorithm to recalculate the metrics and construct a new routing table. Once all the routing tables are, updated convergence is complete. Figure 4 shows that EIGRP performs better in terms of network convergence, followed by OSPF and RIP. 


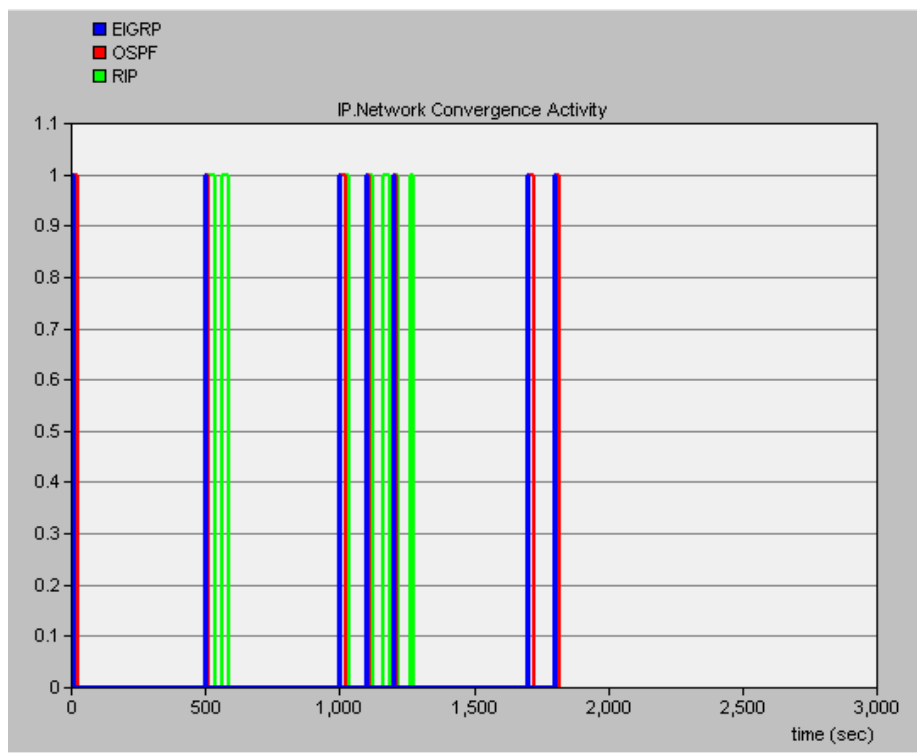

Figure 4. Network Convergence

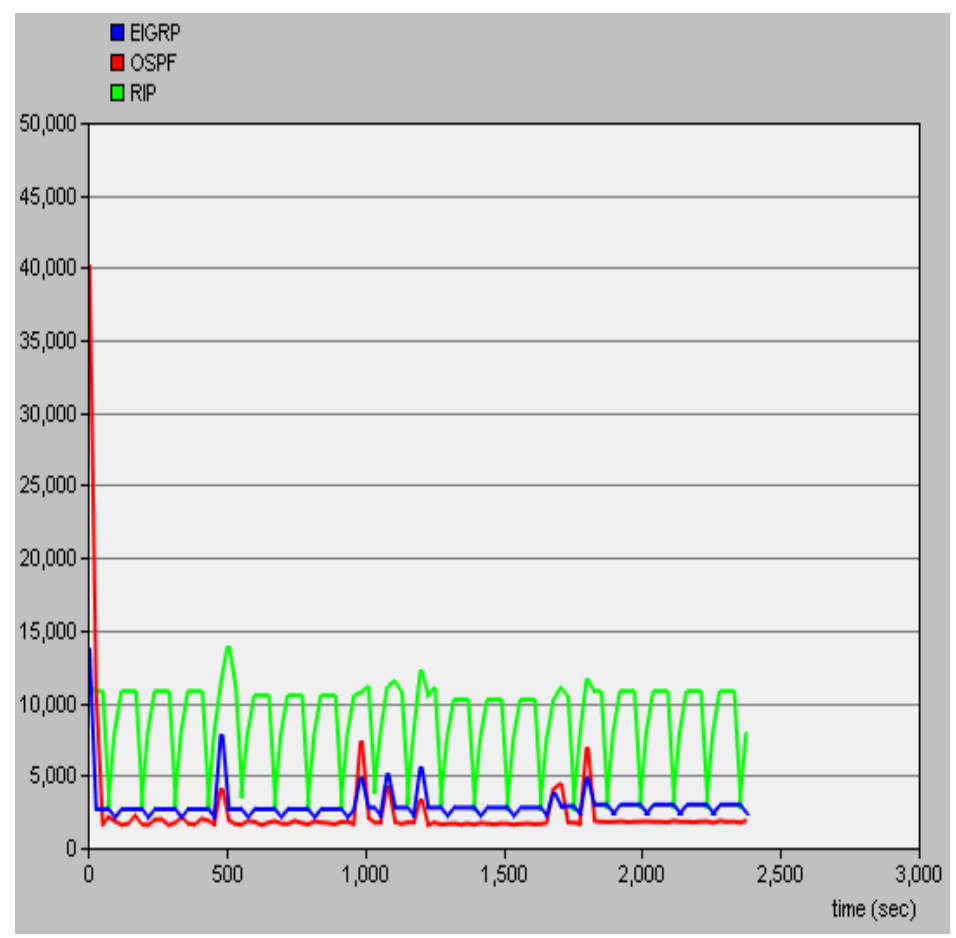

Figure 5. Routing protocols traffic sent (bits/sec)

Figure 5, shows that RIP generates its own traffic continuously regardless of network topology changes; whereas OSPF and EIGRP broadcast their routing table, updates only when network topology changes. It is also observed in Figure 6 that maximum drop of the packets occur in RIP, as the network topology changes. 
Table 5 shows that in normal traffic senerio, all protocols behave almost in same manner, however in worst case when link between regional PDC to super PDC fails; EIGRP performs best. The end to end delay from distributed PMUs to regional PDC is approximately $9 \mathrm{~ms}$ and from regional PDCs to super PDC is $40 \mathrm{~ms}$ in worst case as shown in Figure 7. Although the performance EIGRP is best but it is cisco propriety protocol, hence can not be used with routers other than cisco.

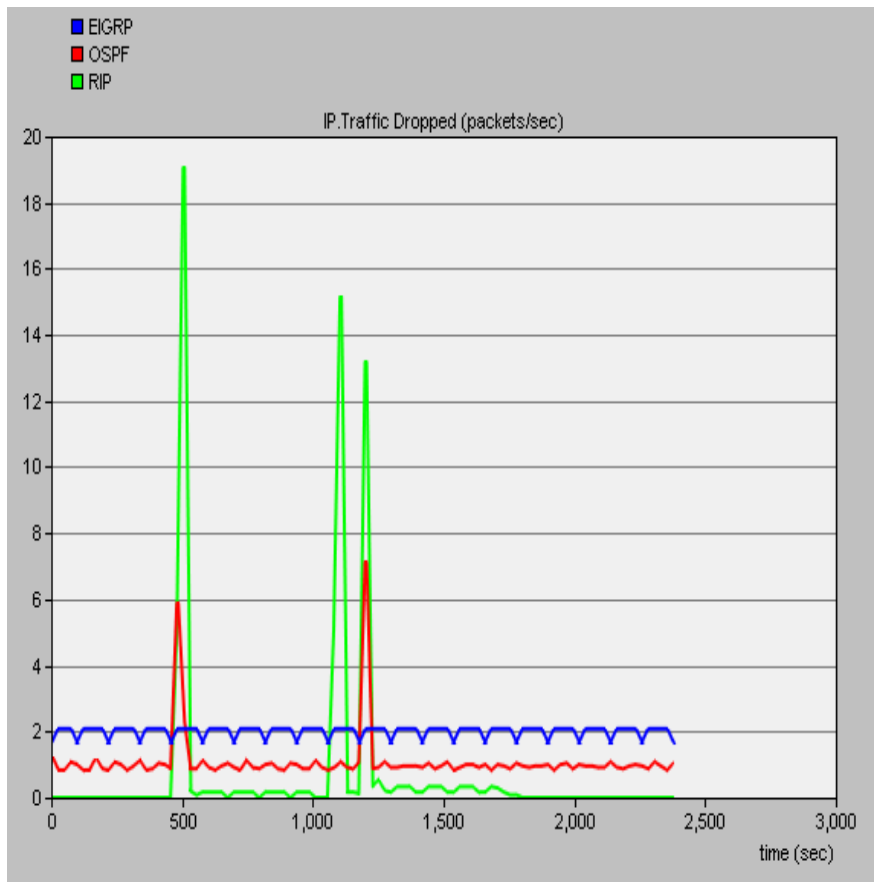

Figure 6. Packets loss in the Network

Table 5. End-to-End delay

\begin{tabular}{|c|c|c|c|c|c|c|}
\hline $\begin{array}{c}\text { Simulation } \\
\text { run time } \\
(\mathrm{sec})\end{array}$ & $\begin{array}{c}\text { PMUs to } \\
\text { Regional } \\
\text { control } \\
\text { center in } \\
\text { case of } \\
\text { RIP } \\
(\mathrm{msec})\end{array}$ & $\begin{array}{c}\text { Regional } \\
\text { control } \\
\text { center to } \\
\text { National } \\
\text { control } \\
\text { center in } \\
\text { case of } \\
\text { RIP } \\
(\mathrm{msec})\end{array}$ & $\begin{array}{c}\text { PMUs to } \\
\text { Regional } \\
\text { control } \\
\text { center in } \\
\text { case of } \\
\text { OSPF } \\
(\mathrm{msec})\end{array}$ & $\begin{array}{c}\text { Regional } \\
\text { control } \\
\text { center to } \\
\text { National } \\
\text { control } \\
\text { center in } \\
\text { case of } \\
\text { OSPF } \\
\text { (msec) }\end{array}$ & $\begin{array}{c}\text { PMUs to } \\
\text { Regional } \\
\text { control } \\
\text { center in } \\
\text { case of } \\
\text { EIGRP } \\
(\mathrm{msec})\end{array}$ & $\begin{array}{c}\text { Regional } \\
\text { control } \\
\text { center to } \\
\text { National } \\
\text { control } \\
\text { center in } \\
\text { case of } \\
\text { EIGRP } \\
\text { (msec) }\end{array}$ \\
\hline 150 & 7.50 & 10.87 & 7.50 & 10.87 & 7.50 & 10.87 \\
\hline 300 & 9.60 & 17.45 & 9.25 & 17.51 & 9.43 & 16.51 \\
\hline 500 & 9.60 & 18.79 & 9.68 & 19.00 & 9.22 & 17.25 \\
\hline 1000 & 9.60 & 18.78 & 10.18 & 17.48 & 9.46 & 17.30 \\
\hline 1100 & 9.60 & 20.74 & 9.43 & 22.41 & 9.44 & 22.23 \\
\hline 1200 & 9.60 & 36.00 & 9.13 & 42.71 & 9.85 & 35.35 \\
\hline 1600 & 7.50 & 20.05 & 7.50 & 22.21 & 7.50 & 20.06 \\
\hline 1700 & 7.50 & 20.00 & 7.50 & 20.32 & 7.50 & 20.06 \\
\hline 1800 & 7.50 & 10.87 & 7.50 & 10.87 & 7.50 & 10.88 \\
\hline
\end{tabular}

It is also observed through Figure 8 that control commands issued by WAMC takes roughly $20 \mathrm{~ms}$ to reach the relay /circuit breaker at substation directly using network. 
International Journal of Distributed and Parallel Systems (IJDPS) Vol.3, No.6, November 2012

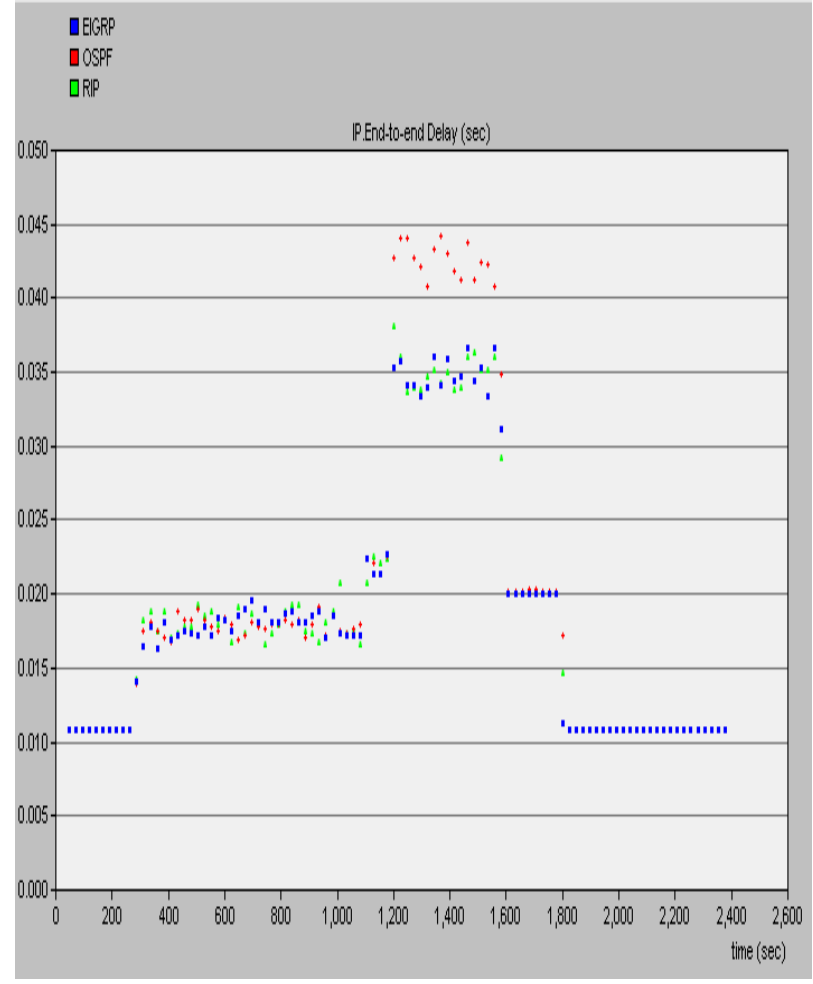

Figure 7. End-to-End delay from Regional control center 2 to National control center

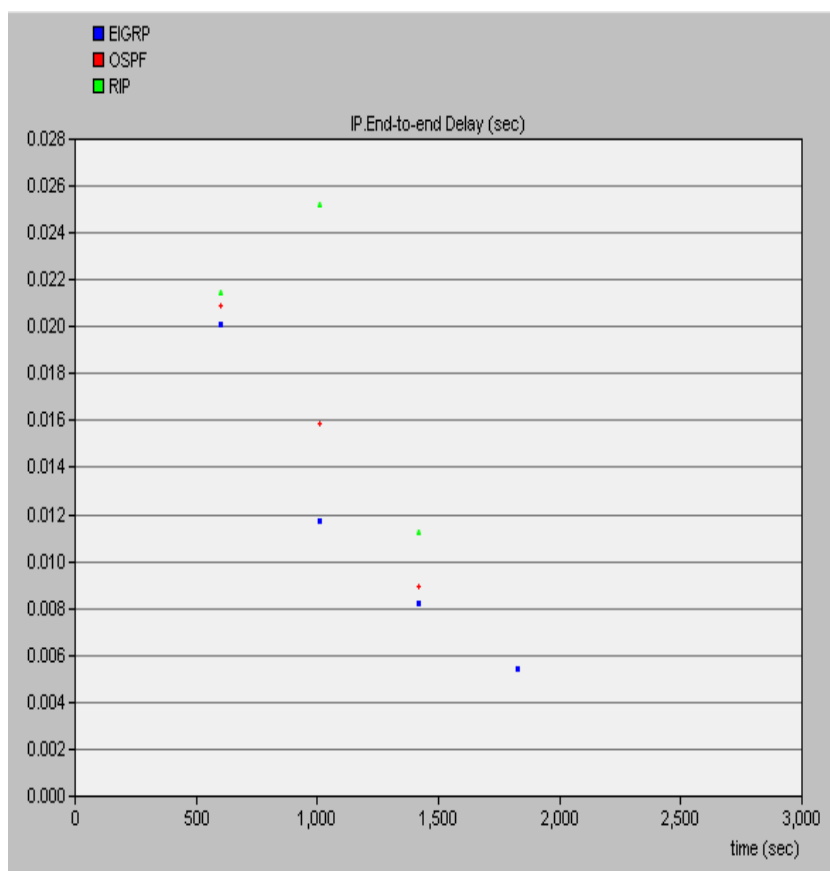

Figure 8. End- to- End delay of WAMC 


\section{Conclusion}

WAMS is the foundation stone of next generation smart grid which provides real time monitoring, protection and control of electric grid. A reliable and high performance communication network is the backbone of such systems. The choice of proper network architecture, communication medium and protocol will play an important role in successful implementation of WAMC. In this paper, an IEEE 14 bus system using minimum PMUs, with varied choices of network protocols had presented in OPNET. In future, OPNET will be integrated with Power system simulator so that the network performance can be evaluated with real traffic of PMUs. We will also evaluate the performance of WAMC with Multi Protocol Label Switching Traffic Engineering (MPLS TE) and Quality of Service (QOS), which is used for load balancing, and prioritizing the traffic.

\section{References}

[1] US-Canada Power System Outage Task Force, Final Report on the August 14, 2003 blackout in the United States and Canada.

[2] M. Zima, M. Larsson, P. Korba, C. Rehtanz, G. Anderson, "Design Aspects for Wide Area Monitoring and Control” IEEE Proceedings, Vol. 93, No. 5, Oct 2004.

[3] M. Chenine, E. Karam, L. Nordstrom, "Modeling and Simulation of Wide Area Monitoring and Control Systems in IP-based Networks”, IEEE Power\& Energy Society General Meeting, July 2009.

[4] K. Tomsovic, D.E.Bakken, V. Venkatasubramanian, A. Bose, "Designing the Next Generation of Real Time Control, Communication, and Computations for large Power Systems", IEEE Proceedings, Special Issue on Energy Infrastructure Systems, Vol. 93, No. 5, pp. 965-979, May 2005.

[5] S. Chakrabarti, E. Kyriakidesi, "Optimal Placement of Phasor Measurement Units for Power System Observability” IEEE Trans. Power Systems, Vol. 23, No. 3, Aug 2008.

[6] IEEE Standard for Synchrophasor Data Transfer for Power Systems, IEEE std C37.118.2 $2^{\mathrm{TM}}$-2011.

[7] A.G. Phadke, J.S. Thorp, "Communication needs for Wide Area Measurement Applications" Critical Infrastructure (CRIS), $5^{\text {th }}$ International Conference, Sep 2010.

[8] Y. Deng, H. Lin, A.G. Phadke, S. Shukla, J.S. Thorp, L. Mili,“Communication Network Modeling and Simulation for Wide Area Measurement Applications" IEEE International Conference on Smart Grid Communications, Oct 2011.

[9] M. Chenine, L. Nordstrom, "Modeling and Simulation of Wide Area Communication for Centralized PMU based Applications", IEEE Trans. On Power Delivery, Vol. 26, No.3, pp. 1372-1380, July 2011.

[10] OPNET Technologies, Inc. "http://www.opnet.com”.

Kiran Gajrani completed her B.E degree in electrical engineering from MBM Engineering College under Jai Narayan Vyas University; Jodhpur, India in 2001. She received the M. Tech in Power Systems from Malaviya National Institute of Technology in 2003 and Pursuing her PhD in electrical engineering department from Rajasthan Technical University, Kota, India.

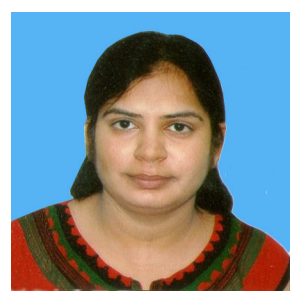

Her research interests include Wide Area Measurement and Control of Power Systems, Wind as renewable energy source, and Communication Networks in Power Systems. 
Krishan Gopal Sharma received the B.E degree in electrical engineering from Rajasthan Agricultural University, Bikaner, India in 2000 and the M. Tech in Power Systems from Malaviya National Institute of Technology in 2003 and Pursuing the PhD from Rajasthan Technical University, Kota, India. Currently working as Associate Professor in the Electrical Engineering of Govt. Engineering College, Ajmer, India.

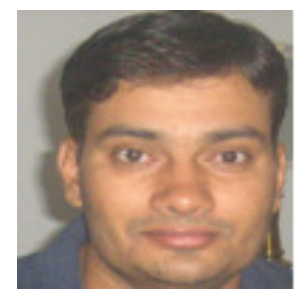

His current research interests include power system dynamics, Wide Area Measurement \& Control, Power System Communication. He is an associate member of Institute of Engineers in India and life time member of ISTE.

Dr Annapurna Bhargava graduated from University College of engineering under Rajasthan Technical University (formerly Engineering College Kota) Kota, Rajasthan, India in 1988. She received her M.Tech in electrical engineering from IIT Delhi, India in 1994 with specialization in Power Systems. Her PhD is in Power Systems from IIT Roorkee. Presently she is Head of the Electrical Engineering Department in University College of Engineering at Rajasthan

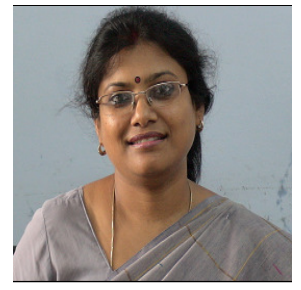
Technical University, Kota, India.

Her research interests include power systems, applications of FACTS \& Artificial intelligence techniques in power system, Power System Optimization, Power System Communication \& Network Security. 